\title{
Synergism Between Southern rice black-streaked dwarf virus and Rice ragged stunt virus Enhances Their Insect Vector Acquisition
}

\author{
Shu Li, Han Wang, and Guohui Zhou
}

Guangdong Province Key Laboratory of Microbial Signals and Disease Control, College of Natural Resources and Environment, South China Agricultural University, Guangzhou, Guangdong 510642, China. Accepted for publication 27 January 2014.

\begin{abstract}
Li, S., Wang, H., and Zhou, G. 2014. Synergism between Southern rice black-streaked dwarf virus and Rice ragged stunt virus enhances their insect vector acquisition. Phytopathology 104:794-799.

Southern rice black-streaked dwarf virus (SRBSDV), a tentative species in the genus Fijivirus, family Reoviridae, is a novel rice virus transmitted by the white-backed planthopper (Sogatella furcifera). Since its discovery in 2001, SRBSDV has spread rapidly throughout eastern and southeastern Asia and caused large rice losses in China and Vietnam. Rice ragged stunt virus (RRSV) (genus Oryzavirus, family Reoviridae) is a common rice virus vectored by the brown planthopper (Nilaparvata

but has not previously caused serious problems in China owing to its low incidence. With SRBSDV's spread, however, RRSV has become increasingly common in China, and is frequently found in co-infection with SRBSDV. In this study, we show that SRBSDV and RRSV interact synergistically, the first example of synergism between plant viruses in the family Reoviridae. Rice plants co-infected with both viruses displayed enhanced stunting, earlier symptoms, and higher virus titers compared with singly infected plants. Furthermore, white-backed and brown planthoppers acquired SRBSDV and RRSV, respectively, from co-infected plants at higher rates. We propose that increased RRSV incidence in Chinese fields is partly due to synergism between SRBSDV and RRSV.
\end{abstract} lugens). RRSV is also widely distributed in eastern and southeastern Asia
A new rice dwarf disease caused by Southern rice blackstreaked dwarf virus (SRBSDV), a recently proposed novel species in the genus Fijivirus (family Reoviridae), was first discovered in Yangxi County, Guangdong Province, China, in 2001 $(28,32)$. Over the past few years, SRBSDV has rapidly spread throughout southern China and northern Vietnam, and has become one of the most important rice pathogens in these regions $(7,33)$. In 2009, it was estimated that up to 315,000 ha of rice (Oryza sativa) growing in 9 Chinese provinces and $>60,000$ ha in 19 provinces of northern Vietnam were infected. In 2010, SRBSDV had spread to 13 provinces in southern China, 28 in northern Vietnam, and 1 in central Vietnam, with 1,601,600 ha of rice infected. In 2011 and 2012 the disease damaged >700,000 and 500,000 ha of rice, respectively, in the two countries (33). The disease has also been found in some areas of Japan (13). Rice plants infected with SRBSDV at the early seedling stage show severe stunting, twisting of leaf tips, and leaf darkening. Infection at later stages leads to small, streaked, black or white, waxy galls on stems; aerial rootlets; branches on stem nodes; and deficient grain weight (33). SRBSDV can be efficiently transmitted by the white-backed planthopper (WBPH) (Sogatella furcifera) in a persistent, circulative-propagative manner but not through egg to the progeny of the insect $(17,32)$. In Southeast Asia, WBPH is a typical long-distance migratory rice pest overwintering in warm tropical or subtropical areas. In early spring, WBPH adults migrate from overwintering sites to China, Japan, and Korea, driven by monsoons. During autumn, when the monsoon direction shifts, WBPHs return to their overwintering locations. In the disease cycle described by Zhou et al. (33), viruliferous WBPH adults carry the virus from south to north via long-distance migration in early spring, transmit the virus to early rice in the newly colonized

Corresponding author: G. Zhou; E-mail address: ghzhou@ scau.edu.cn

http://dx.doi.org/10.1094/PHYTO-11-13-0319-R

(c) 2014 The American Phytopathological Society areas, and lay eggs on the plants. Thus, upon hatching, WBPH population sizes and infection rates on early rice are magnified. The virus then spreads to early and late summer rice, leading to severe outbreaks of the viral disease.

Rice ragged stunt virus (RRSV) (genus Oryzavirus, family Reoviridae) was first described in 1976 and is distributed in eastern and southeastern Asia (6). Following its initial discovery in China in 1978, it has been distributed sporadically, with severe occurrences in some years and localized outbreaks in others. Rice plants infected with RRSV show stunting, leaf edge serration, darkened green coloring on leaves, twisting of leaf tips, and vein swelling or galls on undersides of leaf blades and outer surfaces of leaf sheaths. RRSV is vectored by the brown planthopper (BPH) (Nilaparvata lugens) in a persistent, circulative-propagative manner, without transovarial passage (6). The BPH is another long-distance migratory rice pest, whose overwintering places and migration pathways are similar to those of WBPH. Rice seedlings are susceptible to RRSV; therefore, the occurrence of the disease is more serious in overwintering sites of BPH such as southern Vietnam (15). However, in contrast to WBPH, BPH immigrate to China at a later growth stage of rice when plants have developed resistance to the virus. Because of its low incidence, RRSV does not constitute a threat to rice production in China (34). With the advent of SRBSDV, however, RRSV has become increasingly common in China over the last several years. Field surveys during 2011 to 2013 indicated that the rate of coinfection with SRBSDV and RRSV was $>10 \%$ in dwarf rice samples from southern China while single infections with SRBSDV and RRSV were $\approx 70 \%$ and $<2 \%$, respectively.

Wang et al. (27) reported that SRBSDV alters host selection preference of insect vectors to enhance its spread, and also of insects vectoring RRSV to produce co-infection with that virus. In this study, we demonstrate that SRBSDV and RRSV interact synergistically. Compared with plants singly infected with SRBSDV or RRSV, we observed that co-infected rice plants presented aggravated symptoms, increased virus titers, and ele- 
vated vector acquisition efficiencies. Consequently, the outbreak of SRBSDV threatens rice production not only directly but also through synergism with RRSV, which enhances vector acquisition and promotes the spread of RRSV.

\section{MATERIALS AND METHODS}

Test plants, viruses, and insects. The rice cultivar used in this study ('Qiuyou-998') was purchased from the Guangdong Academy of Agricultural Sciences, Guangzhou, China. Water planting of rice was conducted according to Yoshida et al. (31). The seed were germinated and sown in a 2-liter beaker half-filled with culture solution ( $\mathrm{pH} 4.5$ to 5.0) (31), where they were maintained until the three- or four-leaf seedling stage. A number of seedlings of uniform size were selected and individually transferred into culture tubes $(2.5 \mathrm{~cm}$ in diameter by $25 \mathrm{~cm}$ in height). The roots of each seedling were immersed in the culture solution ( $\mathrm{pH} 4.5$ to 5.0). The seedlings were cultured in an illuminated growth incubator $\left(27^{\circ} \mathrm{C} ; 16 \mathrm{~h}\right.$ of light and $8 \mathrm{~h}$ of darkness).

SRBSDV and RRSV isolates were collected from infected field rice in Guangzhou, Guangdong Province, China, and were WBPH and BPH transmitted, respectively, and maintained on Qiuyou998 rice plants grown in insect-proof greenhouses at our laboratory.

WBPHs and BPHs were collected from field rice plants in the suburb of Guangzhou, Guangdong Province, China and reared on healthy rice plants for three generations in an illumination incubator at 25 to $27^{\circ} \mathrm{C}$. After the plants on which the planthoppers were reared were confirmed negative for SRBSDV and RRSV by RT-PCR, as described below, WBPH nymphs were transferred to SRBSDV-infected or healthy rice plants and $\mathrm{BPH}$ nymphs were reared on RRSV-infected or healthy rice plants. Some of the second-generation, late-stage WBPH or BPH nymphs reared on SRBSDV- or RRSV-infected rice plants were individually subjected to reverse-transcription polymerase chain reaction (RT-PCR) using One Step RNA PCR kit (AMV) (TaKaRa, Dalian, China) and the specific primers for SRBSDV (5'-CGCGTCATCTCAAACTACAG-3' and 5'-TTTGTCAGCA TCTAAAGCGC- $\left.3^{\prime}\right)$ and RRSV (5'-CGCCGTATCTAACGTTCC AG-3' and 5'-TGCCGCGACATAATCAAC-3') (27). Viruliferous $\mathrm{WBPH}$ and $\mathrm{BPH}$ populations showing high amplification rates of viral genetic elements $(92 \%, 46$ of 50 for SRBSDV and $80 \%, 40$ of 50 for RRSV) were used for inoculations.

Five late-stage WBPH or BPH nymphs reared on SRBSDV- or RRSV-infected rice plants for two generations were collected and transferred to individual virus-free rice seedlings at the three- to four-leaf stage cultured separately in a tube in an illuminated growth incubator $\left(27^{\circ} \mathrm{C} ; 16 \mathrm{~h}\right.$ of light and $8 \mathrm{~h}$ of darkness $)$. At least 30 rice seedlings were used for each inoculation. After a 24-h exposure, all insects were removed manually. Rice plants singly infected with SRBSDV or RRSV were obtained by inoculation with viruliferous WBPHs or BPHs, respectively, and plants doubly infected with SRBSDV and RRSV were obtained by inoculation with both viruliferous WBPHs and BPHs. A small amount of second-leaf tissue was collected at 9, 15, and 20 days after the 24-h insect exposure (days postinoculation [dpi]), wrapped with tin foil, quick-frozen in liquid nitrogen, and stored in a freezer at $-70^{\circ} \mathrm{C}$. All rice plants were screened by RT-PCR at 20 dpi. Virus-positive samples were defined as diseased rice plants. In all, 20 to 30 plants with single or dual infection were used for virus quantification and acquisition experiments.

Observation of symptoms. At 9, 15, and $20 \mathrm{dpi}$, plant height (from the base of the stem to the tip of the second flat leaf) of each diseased rice plant was measured, and leaf tips were examined for twisting. Rice seedlings that had been inoculated with the same number of virus-free vectors (mock inoculated) served as healthy rice controls. At least six rice plants were examined per treatment.

SRBSDV and RRSV quantification by RT quantitative PCR. Total RNA was extracted from frozen leaves using Trizol RNAiso Plus (Invitrogen, Boston), and then treated with DNase I (TaKaRa). The purity and concentration of total RNA were determined by spectrophotometry. Total RNA samples with A260/A280 ratios of 1.9 to 2.1 and A260/A230 ratios greater than 2.0 were used as templates for RT quantitative PCR (RT-qPCR).

RT-qPCR primers (Table 1) were designed using Primer Express (version 3.0; Applied Biosystems, Foster City, CA) based on the S10 sequence of an SRBSDV Guangdong isolate and the S8 sequence of an RRSV Philippine isolate. Total RNA was reverse-transcribed into cDNA using a PrimeScript RT reagent kit (TaKaRa). The RT reaction mixture consisted of $2 \mu$ of $5 \times \mathrm{RT}$ buffer, $0.5 \mu \mathrm{l}$ of RT Enzyme Mix I, $1 \mu \mathrm{l}$ of RT primers (Table 1), $6 \mu$ of RNase-free double-distilled (dd) $\mathrm{H}_{2} \mathrm{O}$, and $1 \mu \mathrm{l}$ total RNA. Thermal cycling conditions for the RT were $42^{\circ} \mathrm{C}$ for $15 \mathrm{~min}$ followed by $95^{\circ} \mathrm{C}$ for 2 min. qPCR was then conducted on a Cycler Dice Real Time System TP800 (TaKaRa) using an SYBR Premix Ex Taq II kit (TaKaRa). The qPCR mixture consisted of $12.5 \mu \mathrm{l}$ of SYBR Premix Ex Taq II, $0.6 \mu$ l each of forward and reverse primers $(10 \mu \mathrm{M}), 2 \mu \mathrm{l}$ of cDNA, and sufficient RNase-free $\mathrm{ddH}_{2} \mathrm{O}$ to yield a final volume of $25 \mu \mathrm{l}$. Thermal cycling conditions were as follows: $95^{\circ} \mathrm{C}$ for $30 \mathrm{~s}$, followed by 40 cycles of $95^{\circ} \mathrm{C}$ for $5 \mathrm{~s}$ and $60^{\circ} \mathrm{C}$ for $30 \mathrm{~s}$. The U6 small nuclear RNA gene of rice was used as a control for relative quantification (14), and $\mathrm{RNase}$-free $\mathrm{ddH}_{2} \mathrm{O}$ was used as a no-template control for all detections. At least six rice plants were used from each treatment, with reactions repeated three times per sample.

Vector virus acquisition efficiencies. Newly emerged virusfree WBPH or BPH adults were released on singly or doubly infected rice plants at 9,15 , and 20 dpi. After $24 \mathrm{~h}$, all insects were transferred to healthy rice plants cultured in a 2-liter beaker, as described above. Seven days after the transfer, the WBPHs and BPHs were screened individually for SRBSDV and RRSV, respectively, by RT-PCR (27) and virus acquisition rates from the original singly or doubly infected rice plants were calculated. The experiment was repeated four or five times using different infected rice plants, and 48 or $60 \mathrm{WBPH}$ or BPH adults were used to determine virus acquisition for every combination.

Statistical analysis. Experimental data were collected and analyzed using the statistical software package SPSS 19.0 (IBM, Armonk, NY). Plant height data were examined by repeated measures analysis of variance. Virus titers in rice plants at the same stage were compared using a $t$ test with Bonferroni correction. Pearson's product moment correlation was used to ex-

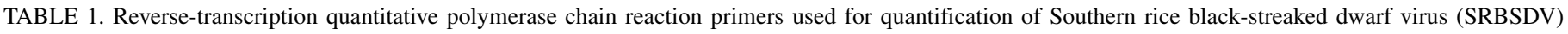
and Rice ragged stunt virus (RRSV)

\begin{tabular}{|c|c|c|c|c|}
\hline Purpose & Target gene (GenBank accession number) & Primer name & Sequence $\left(5^{\prime}-3^{\prime}\right)$ & Size of expected amplicon (bp) \\
\hline SRBSDV & S10 (EU784840) & $\begin{array}{l}\text { SRBSDV CP-F } \\
\text { SRBSDV CP-R }\end{array}$ & $\begin{array}{l}\text { tcatcattagcgcgactagttca } \\
\text { cgtcactcggcgtcgataa }\end{array}$ & 64 \\
\hline RRSV & S8 (AF486811) & $\begin{array}{l}\text { RRSV CP-F } \\
\text { RRSV CP-R }\end{array}$ & $\begin{array}{l}\text { ggctgagcgtgcggtta } \\
\text { tcagccttgatatcgttgtagca }\end{array}$ & 66 \\
\hline Reference & U6 (S83742) & $\begin{array}{l}\text { U6-F } \\
\text { U6-R }\end{array}$ & $\begin{array}{l}\text { cgataaaattggaacgatacaga } \\
\text { atttggaccatttctcgatttgt }\end{array}$ & 72 \\
\hline
\end{tabular}


amine the relationship between virus titers and symptoms of dwarfing and leaf tip twisting in rice, and the relationship between virus titers in rice and vector virus acquisition efficiency.

\section{RESULTS}

Aggravated symptoms in plants with mixed infections. At 9 dpi, rice plants co-infected with SRBSDV and RRSV were, on average, $12.3 \%$ shorter in height than healthy plants. This difference was significant $(F=3.75$, df $=22, P=0.026)$, whereas no significant difference in average height was found between singly infected and healthy rice plants. At $15 \mathrm{dpi}$, average heights of rice plants infected with SRBSDV, RRSV, or both viruses were $38.8,24.9$, and $49.2 \%$ lower, respectively, than healthy plants, with the differences between the three types of infected plants and the controls being significant $(F=103.829$, df $=22, P<0.0001)$. Rice plants co-infected with SRBSDV and RRSV were, on average, 16.7 and $32.3 \%$ shorter, respectively, than rice plants singly infected with SRBSDV and RRSV, which was a significant difference $(F=103.829$, df $=22, P<0.0001)$. At $20 \mathrm{dpi}$, rice plants infected with SRBSDV, RRSV, or both viruses were 56.8, 44.3 , and $67.2 \%$ shorter, respectively, than healthy rice; the differences between the three types of infected plants and the control were significant $(F=290.06$, df $=22, P<0.0001)$. Co-infected rice plants on average were 24.5 and $41.6 \%$ shorter than rice plants singly infected with SRBSDV and RRSV, respectively, with the differences between co-infected and singly infected rice being significant $(F=290.06, \mathrm{df}=22, P<0.0001)$ (Fig. 1$)$. These results demonstrate that rice plants with mixed SRBSDV and RRSV infection presented aggravated stunted growth. At 15 dpi, $50 \%$ of co-infected rice plants showed leaf tip twisting, whereas singly infected plants were symptom-free. At $20 \mathrm{dpi}, 66.7,50$, and $75 \%$ of rice plants infected with SRBSDV, RRSV, or both viruses, respectively, had twisted leaf tips (Table 2). Thus, rice plants coinfected with SRBSDV and RRSV exhibited symptoms earlier than rice plants singly infected with these viruses.

Increased titer of the two viruses in co-infection. Detection of SRBSDV and RRSV was achieved by RT-qPCR with cycle threshold values of target and reference genes of 23 to $38\left(R^{2}=\right.$ 0.993 to 0.999 ) and detection efficiency of 90.6 to $103.2 \%$ with a melting temperature $(\mathrm{Tm})$ of $83 \pm 0.5^{\circ} \mathrm{C}$. Single peaks were observed for all dissociation curves. Therefore, we used this method to characterize SRBSDV and RRSV titers in rice plants. At 9 dpi, no significant difference in SRBSDV titers was found between rice plants singly infected and those co-infected with RRSV $(F=5.328$, df $=16, P=0.211)$ but RRSV titers in coinfected rice were 1.94 times higher than those in singly infected rice (Fig. 2). This difference was significant $(F=5.114$, df $=16$, $P=0.02)$. At $15 \mathrm{dpi}$, SRBSDV and RRSV titers in co-infected rice plants were both significantly higher than in rice plants infected with either SRBSDV (2.06 times higher; $F=5.523, \mathrm{df}=$ $22, P<0.0001)$ or RRSV (1.76 times higher; $F=4.346$, df $=26$, $P=0.040)$. At $20 \mathrm{dpi}$, SRBSDV titers in co-infected rice were significantly higher than those in singly infected rice (1.43 times; $F=7.538$, df $=26, P<0.0001$ ), whereas no significant difference in RRSV titers was found between rice plants singly infected and those co-infected with SRBSDV $(F=0.488$, df $=28, P=0.744)$.

Virus titers in infected rice plants were negatively correlated with plant height. More specifically, a negative correlation was observed between plant height and SRBSDV titers in SRBSDVinfected rice $(r=0.583$, df $=29, P<0.0001)$, RRSV titers in RRSV-infected rice $(r=0.664$, df $=29, P<0.0001)$, and SRBSDV and RRSV titers in co-infected rice $(r=0.704, \mathrm{df}=31$, $P<0.0001$ for SRBSDV and $r=0.670, \mathrm{df}=31, P<0.0001$ for RRSV).

Increased virus acquisition efficiency of vectors due to coinfection. At 9 dpi, $26.7 \pm 5 \%$ and $34.1 \pm 6 \%$ of WBPHs acquired SRBSDV from SRBSDV-infected and co-infected rice, respectively, a nonsignificant difference $(F=1.161$, df $=8, P=0.679)$. In contrast, $26.0 \pm 3 \%$ and $37.5 \pm 2 \%$ of BPHs acquired RRSV from RRSV-infected and co-infected rice, respectively, which was a significant difference $(F=1.159, \mathrm{df}=8, P=0.014)$. At $15 \mathrm{dpi}$,

TABLE 2. Observation of twisted leaf tip symptoms in rice plants infected with Southern rice black-streaked dwarf virus (SRBSDV) and Rice ragged stunt virus (RRSV)

\begin{tabular}{lccc}
\hline & \multicolumn{3}{c}{ Infected with $^{\mathrm{a}}$} \\
\cline { 2 - 4 } Days after infection & SRBSDV & RRSV & SRBSDV+RRSV \\
\hline 9 & $0(6)$ & $0(6)$ & $0(8)$ \\
15 & $0(6)$ & $0(6)$ & $4(8)$ \\
20 & $4(6)$ & $3(6)$ & $6(8)$ \\
\hline
\end{tabular}

a Numbers in each column indicate the number of plants with a twisted leaf tip and numbers in parentheses indicate the number of plants observed.

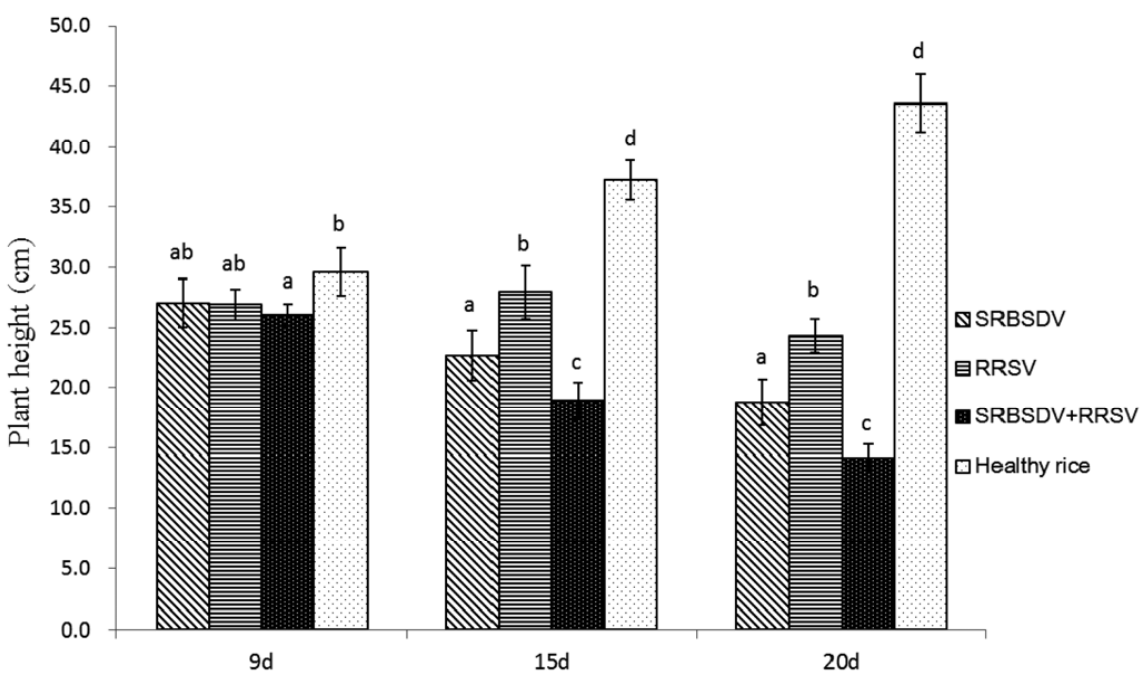

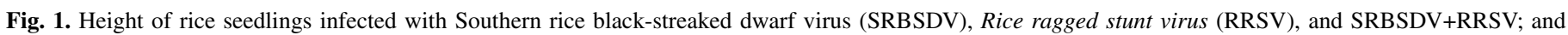

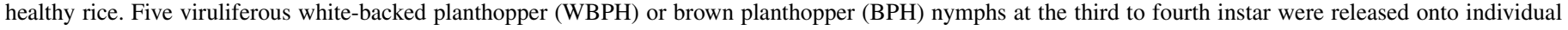

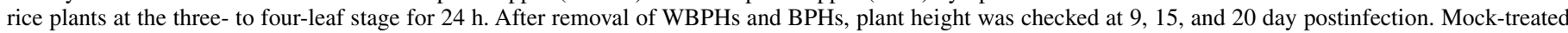

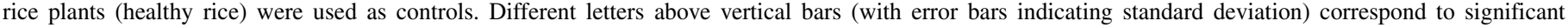

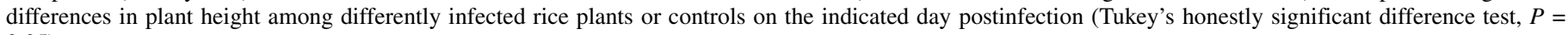
$0.05)$. 
SRBSDV acquisition efficiency of WBPHs fed on co-infected rice $(73.3 \pm 5 \%)$ was significantly higher than in those fed on SRBSDV-infected rice $(45.3 \pm 4 \%)(F=7.938, \mathrm{df}=8, P=0.01)$. RRSV acquisition efficiency of BPHs fed on co-infected rice $(74.3 \pm 5 \%)$ was also significantly higher than that of BPHs fed on RRSV-infected rice $(55.0 \pm 5 \%)(F=2.054$, df $=8, P=0.05)$. At $20 \mathrm{dpi}$, SRBSDV acquisition efficiency of WBPHs fed on coinfected rice $(92.9 \pm 5 \%)$ was significantly higher than in those fed on SRBSDV-infected rice $(71.1 \pm 5 \%)(F=1.548, \mathrm{df}=8, P=$ 0.03). RRSV acquisition efficiency of BPHs fed on co-infected rice $(95.3 \pm 3 \%)$ was also significantly higher than in BPHs fed on RRSV-infected rice $(80 \pm 7 \%)(F=0.01$, df $=8, P=0.05)$ (Fig. 3).

Virus titers in plants were positively correlated with vector virus acquisition efficiency. SRBSDV acquisition efficiency of WBPHs was positively correlated with SRBSDV titers in SRBSDV-infected rice $(r=0.783$, df $=14, P=0.001)$ and coinfected rice $(r=0.848, \mathrm{df}=14, P<0.0001)$, while RRSV acquisition efficiency of BPHs was positively correlated with RRSV titers in RRSV-infected rice $(r=0.692, \mathrm{df}=14, P=0.006)$ and co-infected rice $(r=0.746, \mathrm{df}=14, P=0.003)$.

\section{DISCUSSION}

Compared with plants infected by SRBSDV or RRSV, coinfected rice plants characterized in this study were more stunted (Fig. 1) and had slower growth (Table 1) but no new symptoms. This situation differs from that of RRSV and Rice grassy stunt virus (genus Tenuivirus, family unassigned) co-infection, which results in yellow syndrome (3); it is instead similar to co-infection
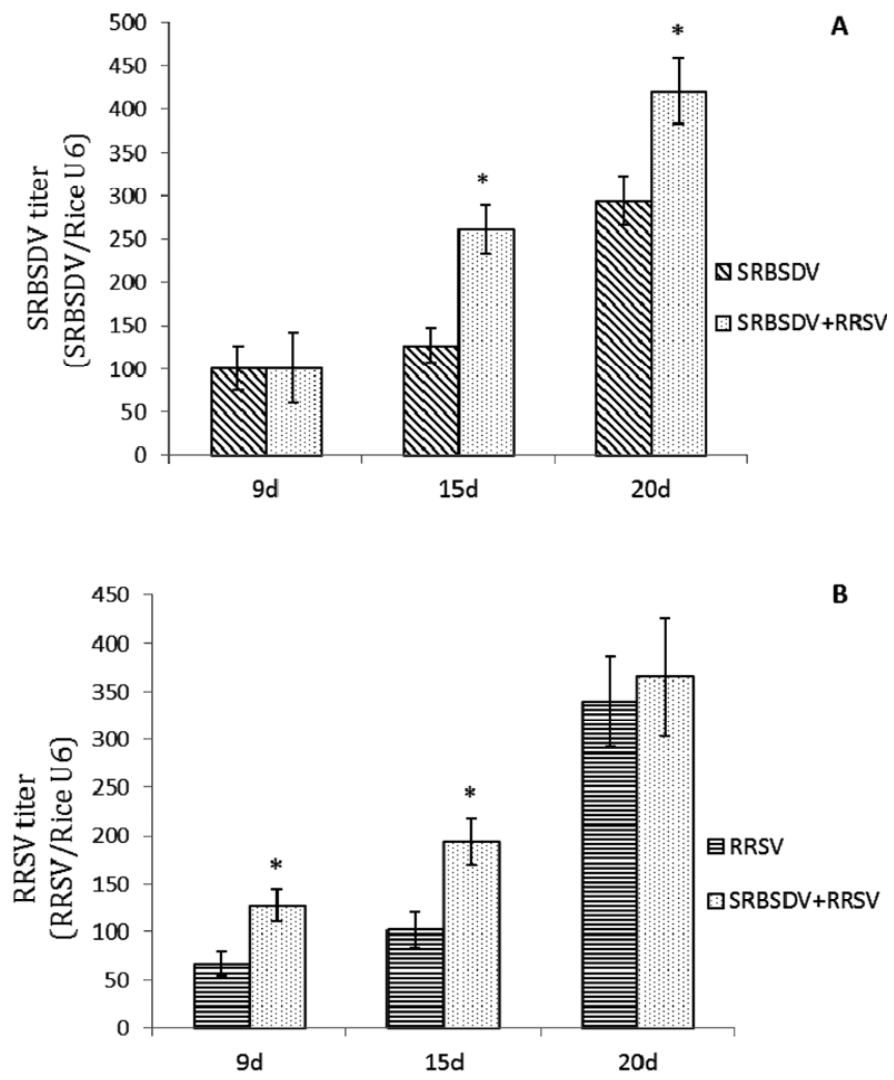

Fig. 2. A, Southern rice black-streaked dwarf virus (SRBSDV) and B, Rice ragged stunt virus (RRSV) titers in infected rice. Virus titers were determined as the relative ratio of SRBSDV S10 or RRSV S8 gene expression to rice U6 gene expression at 9,15 , and 20 days postinfection. Asterisks indicate a significant difference between single infection by SRBSDV or RRSV and mixed infection by both viruses on the indicated day postinfection ( $t$ test with Bonferroni correction, $P<0.05$ ). with Panicum mosaic virus (genus Panicovirus, family Tombusviridae) and its satellite virus that causes aggravated dwarfing, mosaic, and necrosis (12). SRBSDV and RRSV co-infection is obviously one of the reasons why virus-infected rice plants in some fields exhibit severe dwarfism and deficient grain weight (unpublished data). SRBSDV and RRSV titers in co-infected rice were higher than titers in SRBSDV or RRSV singly infected rice, suggesting that the patterns of synergism between SRBSDV and RRSV promote their replication. Patterns of synergism in which replication is mutually stimulated are frequently observed between virus congeners, such as in synergisms between Wheat streak mosaic virus (WSMV) (genus Tritimovirus, family Potyviridae) and Maize chlorotic mottle virus (MCMV) (genus Machlomovirus, family Tombusviridae) (9), and between Cymbidium mosaic virus (genus Potexvirus, family Alphaflexiviridae) and Odontoglossum ringspot virus (genus Tobamovirus, family Virgaviridae) (8). There have also been reports of viruses from different families enhancing one another's replication, such as in the synergism between WSMV and Triticum mosaic virus (TriMV) (genus Poacevirus, family Potyviridae) (24). To our knowledge, however, such synergistic behavior has not been previously reported between viruses in the family Reoviridae. SRBSDV and RRSV are members of the family Reoviridae; they both exist only in phloem cells $(6,32)$ and, thus, likely have similar mechanisms for utilizing host components to replicate. Interaction between these two viruses would consequently promote, rather than inhibit, their replication. The mechanism associated with this interaction is worthy of further study.

We found that SRBSDV and RRSV titers in rice plants were positively correlated with the symptoms of dwarfing and leaf tip
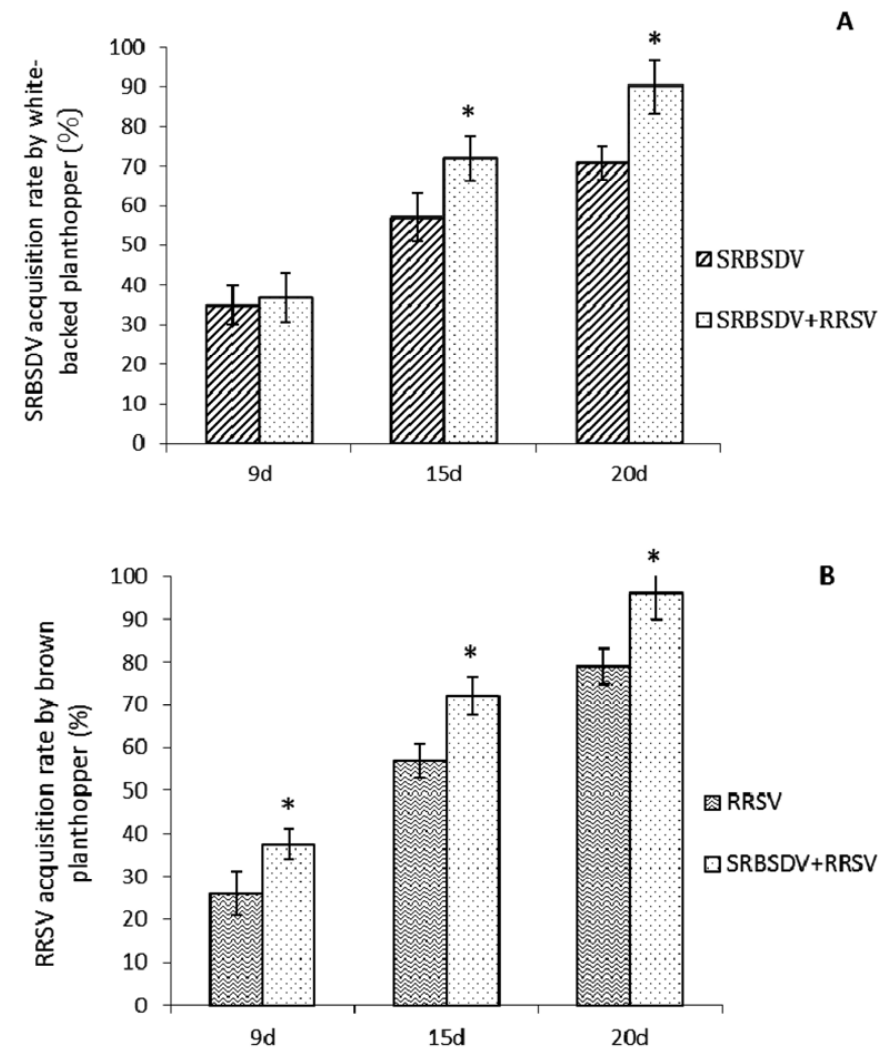

Fig. 3. Virus acquisition rates of $\mathbf{A}$, white-backed planthopper and $\mathbf{B}$, brown planthopper from infected rice. Planthoppers were fed $24 \mathrm{~h}$ on rice plants infected with Southern rice black-streaked dwarf virus (SRBSDV), Rice ragged stunt virus (RRSV), and SRBSDV+RRSV, and detected individually by reverse-transcription polymerase chain reaction after they were transferred to healthy rice plants for 7 days for the virus incubation. Asterisks indicate a significant difference between the two columns for each time point $(t$ test with Bonferroni correction, $P<0.05$ ). Vertical bars represent a standard error value. 
twisting. Matsukura et al. (13) demonstrated that SRBSDV accumulation in plants is correlated with the appearance of symptoms. Previous research has shown that plants co-infected with WSMV and MCMV present increased virus titers, more intense chlorosis, and higher density of chlorotic spots compared with singly infected plants (20). In addition, titers of East African cassava mosaic virus (genus Begomovirus, family Geminiviridae) and African cassava mosaic virus (genus Begomovirus, family Geminiviridae) in co-infected plants were, on average, 2.2 and 5.7 times higher, respectively, than those in singly infected plants, with co-infection resulting in aggravated symptoms (5).

Rice plants co-infected with SRBSDV and RRSV exhibited symptoms earlier than singly infected plants, presumably because of synergistic interaction between both viruses promoting the transport of virus in phloem. Increasing experimental evidence and data exist showing that plant virus movement proteins (MPs) are functionally homologous, despite their lack of sequence homology. As a consequence, the MP of different species, and even different families, can complement and mediate the systematic transport and synergism of heterologous viruses $(2,19$, 23). The protein encoded by open reading frame 3 of Groundnut rosette virus (genus Umbravirus) represents a class of trans-acting long-distance movement factors that can facilitate trafficking of Tobacco mosaic virus (TMV) (genus Tobamovirus, family Virgaviridae) (19). The MPs of Red clover mottle virus (genus Comovirus, family Secoviridae) and TMV can complement one another and promote synergism between their viruses (25). P7-1 of SRBSDV and P6 of RRSV are recognized as MPs $(10,30)$, and their sequence identity is $49.0 \%$. Whether they complement one another remains to be determined.

RNA silencing serves as an antiviral defense system in response to virus challenge in plants. RNA silencing suppressor (RSS) is one of the crucial factors used by viruses to overcome host silencing and infect host plants $(1,4)$. Studies have shown that viral synergism is often associated with the action of RSS proteins $(16,18,26)$. The helper component proteinase of potyviruses has been shown to mediate synergism with viruses from eight other genera $(16,21)$, while the $2 \mathrm{~b}$ protein mediates synergism between Cucumber mosaic virus (genus Cucumovirus, family Bromoviridae) and Turnip mosaic virus (genus Potyvirus, family Potyviridae) (22). Protein P6s of SRBSDV and RRSV has been identified as the RRSs of these two viruses $(11,30)$; their sequence homology is $46.9 \%$ but their possible role in the synergism between SRBSDV and RRSV requires further investigation.

SRBSDV-infected rice can attract RRSV-viruliferous BPHs, thus aggravating SRBSDV and RRSV co-infection (27). The green peach aphid, Myzus persicae (Hemiptera: Aphididae), and the potato aphid, Macrosiphum euphorbiae (Hemiptera: Aphididae), both preferentially settle on plants co-infected with Potato virus $Y$ (PVY) (genus Potyvirus, family Potyviridae) and Potato leafroll virus (PLRV) (genus Polerovirus, family Luteoviridae) rather than singly infected plants (21). Our results indicate that SRBSDV and RRSV co-infection increases virus acquisition efficiency by their respective vectors. In previous studies, WSMV and TriMV were transmitted by the wheat curl mites (Aceria tosichella) at higher efficiencies from co-infected plants than from singly infected plants (24). SRBSDV and RRSV mixed infection may promote higher transmission rates and accelerate epidemic of both viruses.

Increased virus acquisition by insect vectors from co-infected plants may not only be due to the increase in virus titers in plants but may also be the result of interaction between the two viruses. Studies have shown that SRBSDV titers in rice are positively correlated with WBPH virus acquisition efficiency (13). In this study, virus acquisition efficiencies of WBPHs and BPHs were positively correlated during most infection stages with SRBSDV and RRSV titers in rice plants. At 20 dpi, however, no significant difference was found between RRSV titers from singly infected and co-infected rice, whereas RRSV acquisition efficiency of BPHs was significantly higher in co-infected plants. A similar example is that of Nicotiana benthamiana co-infected with Tomato chlorosis virus (ToCV) (genus Crinivirus, family Closteroviridae) and Tomato infectious chlorosis virus (genus Crinivirus, family Closteroviridae) (29), where ToCV titers decreased during co-infection compared with single infection but little change was observed in the efficiency of ToCV acquisition by the banded wing whitefly (Trialeurodes abutilonea). The authors of that study suggested that virus concentration in plants was not the only factor impacting vector acquisition efficiency, and that acquisition efficiency may possibly also be associated with the interaction of viral proteins in the host. In PLRV and PVY coinfected plants, no significant increase in virus titers was observed (21) but virus acquisition efficiency by green peach aphids was significantly increased. The authors of that study speculated that co-infection elevated plant amino acids and soluble carbohydrate concentrations in plants, subsequently affecting vector biology. In our study, synergistic interaction between SRBSDV and RRSV increased the virus acquisition efficiency of their respective vectors, and could promote the SRBDV outbreaks and RRSV epidemics. To confirm this hypothesis, the significance of SRBSDV and RRSV co-infection requires further investigation.

\section{ACKNOWLEDGMENTS}

This research was supported by the National Natural Science Foundation of China (31272012 and 31071661), the International Science \& Technology Cooperation Program of China (2012DFA31220), and the Special Fund for Agroscientific Research in the Public Interest (201003031 and 201303021). We thank J. Xue for carrying out greenhouse maintenance.

\section{LITERATURE CITED}

1. Alvarado, V., and Scholthof, H. B. 2009. Plant responses against invasive nucleic acids: RNA silencing and its suppression by plant viral pathogens. Semin. Cell Dev. 20:1032-1040.

2. Atabekov, J. G., and Taliansky, M. E. 1990. Expression of a plant viruscoded transport function by different viral genomes. Adv. Virus Res. 38:201-248.

3. Du, P. V., Cabunagan, R. C., Cabauatan, P. Q., Choi, H. S., Choi, I. R., Chien, H. V., and Huan, N. H. 2007. Yellowing syndrome of rice: etiology, current status and future challenges. Omonrice 15:94-101.

4. Dunoyer, P., and Voinnet, O. 2005. The complex interplay between plant viruses and host RNA-silencing pathways. Curr. Opin. Plant Biol. 8:415423.

5. Fondong, V. N., Pita, J. S., Rey, M. E. C., Kochko, A. D., Beachy, R. N., and Fauquet, C. M. 2000. Evidence of synergism between African cassava mosaic virus and a new double-recombinant Geminivirus infecting cassava in Cameroon. J. Gen. Virol. 81:287-297.

6. Hibino, H., Roechan, M., Sudarisman, S., and Tantera, D. H. 1997. A virus disease of rice (Kerdil hampa) transmitted by brown planthopper, Nilaparvata lugens Stal in Indonesia. Contr. Centr. Res. Inst. Agric. Bogor No. 35:1-15.

7. Hoang, A. T., Zhang, H. M., Yang, J., Chen, J. P., Hébrard, E., Zhou, G. H., Vinh, V. N., and Cheng, J. A. 2011. Identification, characterization, and distribution of Southern rice black-streaked dwarf virus in Vietnam. Plant Dis. 95:1063-1069.

8. Hu, W. W., Wong, S. M., Loh, C. S., and Goh, C. J. 1998. Synergism in replication of Cymbidium mosaic potexvirus (CymMV) and Odontoglossum ringspot tobamovirus (ORSV) RNA in orchid protoplasts. Arch. Virol. 143:1265-1275.

9. Scheets, K. 1997. Maize chlorotic mottle machlomovirus and Wheat streak mosaic rymovirus concentrations increase in the synergistic disease corn lethal necrosis. Phytopathology 242:847-852.

10. Liu, Y., Jia, D., Chen, H., Chen, Q., Xie, L., Wu, Z., and Wei, T. 2011. The P7-1 protein of Southern rice black-streaked dwarf virus, a Fijivirus, induces the formation of tubular structures in insect cells. Arch. Virol. 156:1729-1736.

11. Lu, Y. H., Zhang, J. F., Xiong, R. Y., Xu, Q. F., and Zhou, Y. J. 2011. Identification of an RNA silencing suppressor encoded by Southern rice black-streaked dwarf virus S6. Sci. Agric. Sin. 44:2909-2917. (In Chinese) 
12. Mandadi, K. K., and Scholthof, K. G. 2012. Characterization of a viral synergism in the monocot brachypodium distachyon reveals distinctly altered host molecular processes associated with disease. Plant Physiol. 160:1432-1452.

13. Matsukura, K., Towata, T., Sakai, J., Onuki, M., Okuda, M., and Matsumura, M. 2013. Dynamics of Southern rice black-streaked dwarf virus in rice and implication for virus acquisition. Phytopathology 103:509-512.

14. Mou, G. P., Wang, K., Xu, D. G., and Zhou, G. H. 2013. Evaluation of three RT-qPCR-based miRNA detection methods using seven rice miRNAs. Biosci. Biotechnol. Biochem. 77:1349-1353.

15. Otuka, A. 2013. Migration of rice planthoppers and their vectored reemerging and novel rice viruses in East Asia. Front. Microbiol. Online publication. doi:10.3389/fmicb.2013. 00309

16. Pruss, G., Ge, X., Shi, X. M., Carrington, J. C., and Vance, V. B. 1997. Plant viral synergism: the potyviral genome encodes a broad-range pathogenicity enhancer that transactivates replication of heterologous viruses. Plant Cell 9:859-868.

17. Pu, L. L., Xie, G. H., Ji, C. Y., Ling, B., Zhang, M. X., Xu, D. L., and Zhou, G. H. 2012. Transmission characteristics of Southern rice blackstreaked dwarf virus by rice planthoppers. Crop Prot. 41:71-76.

18. Ratcliff, F., Harrison, B. D., and Baulcombe, D. C. 1997. A similarity between viral defense and gene silencing in plants. Science 276:15581560 .

19. Ryabov, E. V., Robinson, D. J., and Taliansky, M. E. 1999. A plant virusencoded protein facilitates long-distance movement of heterlogous RNA. Proc. Natl. Acad. Sci. USA 96:1212-1217.

20. Schedts, K. 1998. Maize chlorotic mottle mottlemachlomo virus and Wheat streak mosaic rymovirus concentrations increase in the synergistic disease corn lethal necrosis. Virology 242:28-38.

21. Srinivasan, R., and Alvarez, J. M. 2007. Effect of mixed viral infections (Potato virus Y-Potato leafroll virus) on biology and preference of vectors Myzus persicae and Macrosiphum euphorbiae (Hemiptera: Aphididae). J. Econ. Entomol. 100:646-655.

22. Takeshita, M., Koizumi, M., Noguchi, M., Sueda, K., Shimura, H., Ishikawa, N., Matsuura, H., Ohshima, K., Natsuaki, T., Kuwata, S., Furuya, N., Tsuchiya, K., and Masuta, C. 2011. Infection dynamics in viral spread and interference under the synergism between Cucumber mosaic virus and Turnip mosaic virus. Mol. Plant-Microbe Interact. 25:18-27.

23. Taliansky, M. E., Malyshenko, S. I., Pshennikova, E. S., and Atabekov, J.
G. 1982. Plant virus-specific transport function. Virology 122:327-331

24. Tatineni, S., Graybosch, R. A., Hein, G. L., Wegulo, S. N., and French, R. 2010. Wheat cultivar-specific disease synergism and alteration of virus accumulation during co-infection with Wheat streak mosaic virus and Triticum mosaic virus. Phytopathology 100:230-238.

25. Tomenius, K. 1990. Function and localisation of movement proteins of Tobacco mosaic virus and Red clover mottle virus. Pages 249-259 in: Cell to Cell Junctions in Plants and Animals. Springer, Berlin, Heidelberg.

26. Vanitharani, R., Chellappan, P., Pita, J. S, and Fauquet, C. M. 2004. Differential roles of $\mathrm{AC} 2$ and $\mathrm{AC} 4$ of Cassava geminiviruses in mediating synergism and suppression of posttranscriptional gene silencing. J. Virol. 78:9487-9498.

27. Wang, H., Xu, D. L., Pu, L. L., and Zhou, G. H. 2014. Southern rice black-streaked dwarf virus alters insect vectors' host orientation preferences to enhance spread and increase Rice ragged stunt virus coinfection. Phytopathology 104:196-201.

28. Wang, Q., Yang, J., Zhou, G. H., Zhang, H. M., Chen, J. P., and Adams, M. J. 2010. The complete genome sequence of two isolates of Southern rice black-streaked dwarf virus, a new member of the genus Fijivirus. J. Phytopathol. 158:733-737.

29. Wintermantel, W. M., Cortez, A. A., Anchieta, A. G., Sakhuja, A. G., and Hladky, L. L. 2008. Co-infection by two Criniviruses alters accumulation of each virus in a host-specific manner and influences efficiency of virus transmission. Virology 98:1340-1345.

30. Wu, J. G., Du, Z. G., Wang, C. Z., Cai, L. J., Hu, M. Q., Lin, Q. Y., Li, Y., and Xie, L. H. 2010. Identification of Pns6, a putative movement protein of RRSV, as a silencing suppressor. Virol. J. 7:335. Online publication. doi:10.1186/1743-422X-7-335

31. Yoshida, S., Forno, D. A., and Gomez, K. A. 1976. Pages 61-64 in: Laboratory Manual for Physiological Studies of Rice, 3rd ed. International Rice Research Institute, Manila, Philippines.

32. Zhou, G. H., Wen, J. J., Cai, D. J., Li, P., Xu, D. L., and Zhang, S. G. 2008. Southern rice black-streaked dwarf virus: a new proposed Fijivirus species in the family Reoviridae. Chin. Sci. Bull. 53:3677-3685.

33. Zhou, G. H., Xu, D. L., Xu, D. G., and Zhang, M. X. 2013. Southern rice black-streaked dwarf virus: a white-backed planthopper-transmitted Fijivirus threatening rice production in Asia. Front. Microbiol. 4. Online publication. doi:10.3389/fmicb.2013.00270

34. Zhou, L. G., Du, J. Y., Li, X. R., and Cao, L. 1982. Research on the Rice ragged dwarf virus in Guangdong. J. Guangdong Agric. Sci. 3:31-34. (In Chinese) 